\title{
"PROPRIEDADE COLETIVA" DAS POPULAÇÕES TRADICIONAIS BRASILEIRAS E OS USI CIVICI NA ITÁLIA
}

Girolamo Domenico Treccani

\section{INTRODUÇÃO}

Este trabalho pretende realizar uma análise preliminar sobre as possíveis convergências entre, de um lado, as formas latino-americanas de acesso à terra e aos recursos naturais e, de outro as experiências já em curso há séculos na Europa, onde alguns grupos sociais conseguiram o reconhecimento do uso coletivo de seus territórios. Uma questão que aqui somente se preanuncia, mas que será necessário aprofundar em estudos futuros, é se a defesa das "terras de uso coletivo" dos povos e comunidades tradicionais da América Latina tem a mesma matriz jurídica dos bens coletivos já reconhecidos na Europa.

A comparação entre estes ordenamentos jurídicos pode ajudar a relativizar o conceito clássico de "propriedade privada" muitas vezes apresentado como a melhor ou, até, a única forma de acesso à terra, permitindo valorizar outras formas de acesso, como aquelas adotadas pelas populações tradicionais.

Nas últimas décadas no Brasil e nos demais países da América Latina muitos povos e comunidades tradicionais que durante séculos tinham permanecido "invisibilizados" entraram na cena política exigindo o reconhecimento de seus direitos. São variados os tipos de organizaçôes que procuram o Poder Público para que sejam reconhecidas como legítimas suas formas de organização específica, suas formas de ocupação das terras e suas maneiras tradicionais de utilizar os recursos naturais. Povos Indígenas, Comunidades Remanescentes de Quilombo e demais Comunidades Tradicionais conseguiram avanços significativos no reconhecimento 


\section{•• Série Direito, Economia e Sociedade}

formal de seus direitos territoriais, mas, na grande maioria dos casos, esses direitos ainda não foram implementados ou estão sob ameaça de não efetivação, como é o caso das políticas adotadas recentemente pelo governo brasileiro contra os povos indígenas e os quilombos. ${ }^{126}$

No caso do Brasil, por exemplo, as recentes políticas adotadas pelo Governo Federal na política de Regularização Fundiária Rural e Urbana (Medida Provisória 759/2016 e Lei 13.465/2017) simplificaram os procedimentos de expedição de títulos ou a celebração de contratos de Concessão de Direito Real de Uso (CDRUs) individuais, facilitando o acesso à propriedade privada ou à gestão privada das terras públicas, enquanto as formas diferenciadas de acesso à terra para as populações tradicionais continuam a terem tramitações tão complexas ${ }^{127}$ que alguns processos demoram décadas. ${ }^{128} \mathrm{O}$ conhecimento de outras experiências jurídicas pode fazer avançar o debate acadêmico e fortalecer as açóes políticas desses povos na luta pelo reconhecimento de seus direitos. Ao mesmo tempo, na Europa renasce o debate sobre os "usos cívicos", isto é, formas tradicionais de uso do território e dos recursos que tinham sido reconhecidos como "válidas" pelos ordenamentos jurídicos de vários países, mas que pareciam ser atualmente formas arcaicas, em desuso e destinadas a desaparecer. ${ }^{129}$

Durante séculos, o ordenamento jurídico brasileiro tem sido um campo dogmático que apresenta diversas normas para regular o "direito de propriedade". Pon-

${ }^{126}$ Ver, entre outros: MOREIRA, Eliane; PIMENTEL, Melissa. O direito à autoidentificação de povos e comunidades tradicionais no Brasil. Revista Fragmentos de Cultura, Goiânia, v. 5, 2, p. 159-170, abr/jun. 2015; LEITE, Ilka Boaventura, As classificaçôes étnicas e as terras de negros no sul do Brasil. In: AFRO-LEITURAS NUER, Florianópolis. 1995.

127 Podem-se citar, por exemplo, o Decreto $1.775 / 96$ sobre povos indígenas e a Instrução Normativa 57/2009 do INCRA sobre quilombos que exigem estudos muito detalhados para identificar estas comunidades, estudos estes, que não são exigidos nas titulações individuais. No mesmo sentido o Parecer 001/2017/GAB/CGU/AGU adotado pela Advogada Geral da União, 19 de julho de 2017, que estende indevidamente a todas as terras indígenas a decisão do ST na PET 3.388/RR estabelecendo o "marco temporal" para todas terras indígenas ou o Parecer da AGU que suspende a tramitação dos processos quilombolas conforme divulgou Fellet em 18 de abril de 2017.

${ }^{128}$ No caso dos quilombos, o processo 178762 está tramitando no Instituto de Terras do Pará desde 1999, a nível federal, mais de dez processos iniciaram a tramitar em 2003.

129 Além dos livros de Paulo Grossi citados abaixo, pode-se referir o livro de Martin (1990), que apresenta o Simpósio Internacional realizado em 1986 em Pieve di Cadore e lembrar e as "Jornadas" promovidas nas últimas décadas pelo Centro Studi e Documentazione Sui Demani Civici e le Proprietà Collettive" da Universidade de Trento. 
to de partida comum era considerar como "universal": um direito privado, individual ou, quando muito, bens pertencentes a pessoas jurídicas. ${ }^{130}$

Por meio da análise das normas de alguns Estados, das decisões da Corte Interamericana de Direitos Humanos e dos trabalhos de alguns juristas dos dois continentes, procuram-se os caminhos iniciais para se verificar a possibilidade de construção de um diálogo entre as experiências brasileira (e latino-americanas) e italiana, visando demonstrar que este debate não aborda questões periféricas no domínio da pesquisa científica jurídica, mas da defesa de direitos fundamentais de última geração a serem efetivados na América Latina e consolidados na Europa.

\section{2. "PROPRIEDADE PARTICULAR" COMO DIREITO "ABSOLUTO"?}

Ao longo da história o direito brasileiro - embora pudéssemos dizer mais genericamente "o Direito" dos diferentes países ocidentais que fincam suas raízes no direito romano, tem sido um campo em que os sistemas legais estatais apresentam diversas regras para regular o "direito de propriedade". Ponto de partida comum é considerar como aplicável a todos os ordenamentos jurídicos, um direito privado, pessoal, individual, de uso exclusivo, ou, como dito acima, quando muito, de bens pertencentes a pessoas jurídicas (no caso dos imóveis rurais as empresas agropecuárias). ${ }^{131}$

${ }^{130}$ No começo do século XX P. Van Wetter (1909, p. 2) afirmava: “a propriedade é, em princípio, um direito ilimitado sobre as coisas”. Em 1911 Leon Duguit (1912, p. 21) defendeu a necessidade de se alterar a doutrina tradicional sobre o direito de propriedade afirmando que: "a propriedade não é um direito; é uma função social”. Segundo Silva e Maciel (2009, p. 254): “já no Direito Romano, a propriedade era um direito absoluto e exclusivo, ao passo que na Idade Média, com o sistema de vassalagens e os laços de fidelidade ligando os senhores ao rei, o direito de propriedade era mais frágil e relativo. Para os juristas, foi com o liberalismo da Era Moderna que esse direito retomou a ideia de propriedade absoluta, com a ascensão da burguesia, que teve seu ápice no século XIX. Mas no século XX, com as políticas intervencionistas do Estado, o Direito passou a entender a propriedade de acordo com sua função social, negando juridicamente a ideia de propriedade absoluta”.

131 O art. 113, 17 da Constituição brasileira de 14 de julho de 1934, incorporou a função social da propriedade no ordenamento jurídico brasileiro: "É garantido o direito de propriedade, que não poderá ser exercido contra o interesse social ou coletivo, na forma que a lei determinar" (grifo nosso). Esta norma foi inspirada pela Constituição alemã de Weimar de 1919 cujo Art. 153, $\$ 2^{\circ}$ previa: "A propriedade impõe obrigações. Seu uso deve constituir, ao mesmo tempo, um serviço para o mais alto interesse comum". Apud Costituzione di Weimar (11 de agosto de 1919). Disponível em: <http://www.dircost.unito.it/cs/pdf/19190811_germaniaWeimar_ita. pdf>. Acesso em: 18 out. 2017. Já a Constituição Mexicana de 1917 previa que o Estado tinha 
Esta posição dogmática, cuja origem pode ser encontrada ainda no direito romano, se consolidou com a revolução industrial, quando os estados nacionais adotaram um conceito de "propriedade" como algo que estava na própria "essência ontológica" das pessoas. Esta posição se cristalizou no artigo 544 do Código Civil Napoleônico de $1804,{ }^{132}$ introduzido no ordenamento jurídico brasileiro pela Constituição Imperial de $1824,{ }^{133}$ incluída em vários códigos nacionais nos séculos XIX e XX e consolidada no artigo 524 do Código Civil Brasileiro de 1916, que permitia ao titular do direito de propriedade de: "usar, gozar e dispor dos seus bens.”

Apesar do artigo 20 do "Estatuto da Terra" (Lei 4.504, 30 de novembro de 1964) ter incluído o respeito da "função social da propriedade", tratava-se sempre uma forma de propriedade imposta de forma uniforme em todo o território nacional, não levando em consideração os diferentes grupos sociais detentores deste direito. Os agentes estatais procuravam "padronizar", "homogeneizar" juridicamente as diferentes situaçōes em regras rígidas e pré-estabelecida durante séculos.

Esta análise preliminar já nos permite compreender que este pretenso "universalismo" dogmático utilizado pelos ordenamentos jurídicos europeus e imposto pelos países ibéricos na América Latina: "só foi possível com base na força com que a intervenção política, económica e militar do colonialismo e do capitalismo modernos se impuseram aos povos e culturas não ocidentais e não cristãos (SANTOS; MENESES, p. 8)". ${ }^{134}$ Ou seja: as normas impostas pelos colonizadores não levaram em consideração os ordenamentos jurídicos preexistentes à invasão. ${ }^{135}$

a possibilidade de limitar o uso da terra: "La nación tendrá en todo tiempo el derecho de imponer a la propiedad privada las modalidades que dicte el interés público`. Constitución Política de Los Estados Unidos Mexicanos. Constitución publicada en el Diario Oficial de la Federación el 5 de febrero de 1917. Disponível em: <http://www.oas.org/juridico/mla/sp/mex/ sp_mex-int-text-const.pdf>. Acesso em: 18 out. 2017.

132 Art. 544: "A propriedade é o direito de gozar e dispor das coisas da maneira a mais absoluta, sem poder fazer o uso proibido pelas leis ou os regulamentos" (tradução nossa).

133 Art. 179. [...] XXII "É garantido o Direito de Propriedade em toda a sua plenitude".

${ }^{134}$ Os mesmos autores afirmam que as diferenças culturais existentes nos demais países fora da Europa foram esquecidas em nome da homogeneização cultural do mundo. Teria acontecido um verdadeiro "epistemicídio", isto é, a supressão dos conhecimentos locais perpetrada por um conhecimento alienígena. Em nome de uma pretensa cultura "universal" considerada "superior", as demais formas de conhecimento foram aniquiladas.

135 Os povos indígenas brasileiros, por exemplo, adotavam um regime de bens não baseado na apropriação particular dos mesmos, desconhecendo o conceito de "propriedade privada". 


\section{BRASIL (AMÉRICA LATINA): A EMERGÊNCIA DE NOVOS DIREITOS}

A partir da década de $1980^{136}$ no Brasil - embora possamos, possivelmente, aplicar essa declaração para os demais países da América Latina - começaram a ser reconhecidas outras formas de acesso à terra, nas quais as reivindicações territoriais de grupos sociais estão intrinsicamente relacionadas às suas identidades. Hoje, na América Latina, diferentes países reconhecem os direitos territoriais dos Povos Indígenas, ${ }^{137}$ das Comunidades Remanescentes de Quilombo ${ }^{138}$ e demais comunidades tradicionais. ${ }^{139}$

O conceito legal de "propriedade" assume, dessa maneira, novas conotações. Os povos indígenas, as comunidades de quilombo e outras populaçôes tradicionais incorporam relações com a terra (posse tradicional, propriedade coletiva, contratos de uso), nas quais o que importa não é o sentido clássico de "propriedade", mas a segurança jurídica diretamente ligada ao uso tradicional/cultural da terra e dos demais recursos naturais. As "Populações Tradicionais" não lutam pelo recebimento de "títulos definitivos de propriedade individual", mas para alcançar o reconhecimento jurídico da garantia de poder usar de forma exclusiva ${ }^{140}$ a terra e seus recur-

136 O I Encontro dos Povos da Floresta, realizado na cidade de Rio Branco (Acre-Brasil), entre 25 e 31 de março de 1989 com a presença de 187 delegados extratores de seringa e indígenas dos estados do Acre, Amazonas, Pará, Amapá e Rondônia, deram origem à "Aliança dos Povos da Floresta". O II Encontro, realizado em Brasília (DF), de 18 a 23 setembro de 2007, além dos representantes da Amazônia, reuniu populaçōes tradicionais da Caatinga, Cerrado, Mata Atlântica, Pampas e do Pantanal. Em 2016 este movimento foi ulteriormente ampliado com a realização, do 5 a 7 de setembro da: "Jornada de Lutas Unitárias dos Trabalhadores e Trabalhadoras e Povos do Campo, das Águas e das Florestas".

137 As Constituiçõos de vários países reconhecem seus direitos territoriais: Argentina (art. 75); Bolívia (art. 230); Brasil (art. 231); Colômbia (art. 171); Equador (arts. 56 e 57); México (art. 4o); Paraguai (arts. 62-64) e Venezuela (art. 119). Também tratados internacionais reconhecem estes direitos, destacamos: a Convenção 169 da Organização Internacional do Trabalho (arts. 13 e 14) e a Declaração das Nações Unidas sobre os Direitos dos Povos Indígena.

138 As Constituiçôes do Brasil (art. 68 do ADCT); Colômbia (art. 7o e Art. Transitório 55); Equador (art. 56, 58 e 257) e Nicarágua (art. 89 a 91) e normas complementares da Bolivia (Ley 173, de 20 de septiembre de 2011); Honduras (Decreto 82-2004); Panamá (Ley 9, de 30 de mayo de 2000); Peru (Ley 28.495, de 6 de abril de 2005) reconhecem seus direitos.

139 No caso do Brasil se pode fazer referência ao Decreto $n^{\circ}$ 6.040, de 07 de fevereiro de 2007.

${ }^{140} \mathrm{O}$ uso exclusivo da terra é uma das exigências apresentadas pelas diversas populações tradicionais, mas no caso das quebradeiras de coco babaçu, presentes sobretudo nos estados do Maranhão, Pará e Tocantins, a luta não é pela "posse ou propriedade" dos imóveis, mas o acesso aos recursos naturais. Shiraishi Neto (2006) mostra como a luta das quebradeiras permitiu a adoção de várias normas municipais conhecidas como: "Leis do Babaçu Livre". 


\section{•• Série Direito, Economia e Sociedade}

sos naturais. Isso ocorre, também, quando o documento é um mero reconhecimento de posse, como no caso dos povos indígenas, ou a celebração de um Contrato de Concessão de Direito Real de Uso (CDRU), em que o domínio da terra permanece público, como acontece com as outras populaçôes tradicionais.

As diferentes experiências têm em comum a busca por dar "visibilidade" às suas propostas e reivindicações territoriais. Na última década, dezenas de comunidades tradicionais adotaram o "mapeamento social" como uma ferramenta para mostrar sua existência ao Estado e solicitar o reconhecimento dos seus direitos. O site da internet "Nova Cartografia Social" nos mostra a íntima conexão entre os territórios ocupados e a identidade desses grupos.

O Projeto Nova Cartografia Social da Amazônia (PNCSA) tem como objetivo dar ensejo à auto-cartografia dos povos e comunidades tradicionais na Amazônia. Com o material produzido, tem-se não apenas um maior conhecimento sobre o processo de ocupação dessa região, mas sobretudo uma maior ênfase e um novo instrumento para o fortalecimento dos movimentos sociais que nela existem. Tais movimentos sociais consistem em manifestações de identidades coletivas, referidas a situações sociais peculiares e territorializadas. Estas territorialidades específicas, construídas socialmente pelos diversos agentes sociais, é que suportam as identidades coletivas objetivadas em movimentos sociais. ${ }^{141}$ (grifo nosso)

Rocha, Treccani et al. (2015, p. 94) mostram como o conceito de "território" utilizado para definir os espaços ocupados pelos povos e comunidades tradicionais não deve ser confundido com o conceito que se utiliza no direito internacional:

Deve-se destacar também que o sentido de território empregado quando trata das populações tradicionais está mais próximo da(s) definição(ōes) atribuída(s) pela antropologia, a qual enfatiza a apropriação e construção simbólica que é feita pelas populações em espaços por elas habitadas; e não como a teoria política e o ordenamento jurídico o concebem (um povo, um território, uma nação). Para o direito, território é um dos elementos formadores do estado e o limite de seu poder.

O conceito de território a ser aplicado, é aquele que consta no art. 13 da Convenção 169 da OIT (Decreto 5.051, de 19 de abril de 2004), que mantém uma relação estreita com sua cultura e valores espirituais:

1. Ao aplicarem as disposições desta parte da Convenção, os governos deverão respeitar a importância especial que para as culturas e valores espirituais dos povos interessados possui a sua relação com as terras ou territórios, ou com ambos, segundo os casos, que eles ocupam ou utilizam de alguma maneira e, particularmente, os aspectos coletivos dessa relação.

${ }^{141}$ Disponível em: <http://novacartografiasocial.com/apresentacao/>. Acesso em: 22 jan. 2017. 
2. A utilização do termo "terras" nos artigos 15 e 16 deverá incluir o conceito de territórios, o que abrange a totalidade do habitat das regiōes que os povos interessados ocupam ou utilizam de alguma outra forma.

Esta realidade prevista no ordenamento jurídico de vários países e nos tratados internacionais chega a questionar alguns dos conceitos clássicos do direito ocidental, pouco propenso a dar espaço ao reconhecimento de direitos coletivos.

No que diz respeito ao Brasil, assiste-se, a partir dos anos 1980, a uma verdadeira efervescência de movimentos que procuram o reconhecimento de seus direitos identitários e territoriais. ${ }^{142}$

No caso dos povos indígenas, comunidades quilombolas e povos e comunidades tradicionais, Oliveira (2017, p. 153) depois de ter afirmado que:

Durante muito tempo, estes grupos foram tidos como incapazes de tomarem decisões e esta visão preconceituosa estava institucionalizada sob a forma de leis e práticas estatais. Por um lado, leis como o Estatuto do Índio (Lei 6.001/1973) e a Convenção 107 da Organização Internacional do Trabalho afirmavam que os povos indígenas deveriam ser "progressivamente integrados à sociedade nacional", dando substrato jurídico a políticas de negação da diversidade e de assimilação forçada.

O mesmo autor (2017, p. 154) reconhece:

A superação deste quadro jurídico, classificado como "tutelar", se deu inicialmente com a promulgação da Constituição Federal de 1988 que reconhece a "organização social, costumes, línguas, crenças e tradições” dos povos indígenas, bem como os direitos originários sobre as terras ocupadas tradicionalmente, dentre outras conquistas importantes.

${ }^{142}$ Neste sentido é significativa a alteração da lista das organizações que integram o "Conselho Nacional dos Povos e Comunidades Tradicionais - CNPCT". O Decreto mais recente mostra o reconhecimento, por parte do governo federal, da diversificação destas comunidades. Enquanto o Decreto de 13 de julho de 2006 apresentava uma lista com 13 representantes, o $\$ 2^{\circ}$ do artigo $4^{\circ}$ do Decreto 8.750 , de 9 de maio de 2016, aumentou esta representação a 29 grupos sociais (os nomes dos novos grupos estão sublinhados e, em itálico, os 13 que se localizam na Amazônia): I - povos indígenas; II - comunidades quilombolas; III - povos e comunidades de terreiro/povos e comunidades de matriz africana; IV - povos ciganos; V - pescadores artesanais; VI - extrativistas; VII - extrativistas costeiros e marinhos; VIII - caiçaras; IX - faxinalenses; X - benzedeiros; XI - ilhéus; XII - raizeiros; XIII - geraizeiros; XIV - caatingueiros; XV - vazanteiros; XVI - veredeiros; XVII - apanhadores de flores sempre vivas; XVIII - pantaneiros; XIX - morroquianos; XX - povo pomerano; XXI - catadores de mangaba; XXII - quebradeiras de coco babaçu; XXIII - retireiros do Araguaia; XXIV - comunidades de fundos e fechos de pasto; XXV - ribeirinhos; XXVI - cipozeiros; XXVII - andirobeiros; XXVIII - caboclos; e XXIX - juventude de povos e comunidades tradicionais. A eles deveriam ser acrescidos os marisqueiros, açorianos, jangadeiros e varjeiros presentes em outras regiōes brasileiras. 


\section{•• Série Direito, Economia e Sociedade}

Já no que diz respeito aos quilombos Boaventura de Sousa Santos (1995, p. 10-11) mostrava os avanços alcançados, mas a precariedade de sua implementação:

O artigo 68 das Disposições Transitórias da Constituição Federal de 1988 prevê a legalização das terras remanescentes de quilombos no Brasil. Constata-se porém que: de 88 a 94, seis anos se passaram e por parte destes grupos, tem havido fraca politização em torno da conquista da regulamentação destes direitos. Mais uma vez, empenhados na luta cotidiana pela conquista da própria sobrevivência, desinformados e desassistidos pelo poder público, correm o risco de permanecerem como estão. ${ }^{143}$

A procura pela "visibilidade" e pelo reconhecimento de seus direitos, que finca suas raízes mais profundas nas diferentes formas de resistência adotadas secularmente pelos povos indígenas e pelos africanos escravizados no Brasil, ganhou uma nova dimensão numérica e política, na segunda metade dos anos oitenta, como mostra Viana (2010, p. 1)

Com a redemocratização em 1985, a promulgação da Constituição de 1988, a decretação de legislaçôes complementares de acesso à terra e o estabelecimento de agências governamentais de apoio ao reconhecimento de direitos comunitários à terra e aos recursos naturais, são criadas as condiçôes legais e institucionais para o atendimento das reivindicaçôes de povos e comunidades tradicionais, representados por novos movimentos sociais institucionalizados, baseados na afirmação de identidade étnicas, raciais e de gênero, associadas à defesa de territórios e ao uso tradicional dos recursos naturais (grifo nosso).

Muitas vezes, porém, a afirmação destas "novas identidades" e "territórios" é acompanhada por conflitos que poderiam ser denominados de "etno-sócio-ambientais" que colocam em xeque as pretensões de reconhecimento dos direitos territoriais dos povos e comunidades tradicionais em relação às demais formas de apropriação destes espaços, de maneira especial por parte de empresas.

Esta disputa não se limita ao uso da terra e da floresta, mas se estende a outras atividades tradicionais, como por exemplo a pesca, que, também, criam seus "espaços territoriais" como os "territórios de pesca”. Assim escreve Rapozo (2015, p. 17):

A pesca na Amazônia tem implicado na construção de territorialidades sociais, ou seja, na demarcação dos espaços sociais na pesca comercial e de subsistência entre os agentes envolvidos o que, consequentemente, tem criado/recriado conflitos sociais pelo acesso aos recursos pesqueiros e (re)configurado as relaçôes de trabalho na atividade pesqueira (grifo nosso).

143 Decorridos treze anos da publicação daquele artigo, pesquisas pessoais, mostram como a situação não melhorou: menos de oitocentos mil hectares foram titulados em favor dos remanescentes das comunidades de quilombos. Se permanecer este ritmo de titulações serão necessários alguns séculos para atender as milhares de comunidades existentes no pais. 
A definição de territorialidade específica muitas vezes se consolida em conflitos com a sociedade do entorno e a política homogeneizante do "direito estatal". Pedro Rapozo (2015, p 137) afirma que:

Compreender a relação de apropriação dos recursos naturais, a formação de territórios tradicionais e a dimensão social dos conflitos estabelecidos pela posse se torna um elemento fundamental [...]. As referências teóricas perpassam os temas dos regimes de propriedade comum, territórios e espaços sociais em disputa e conflito pela apropriação de recursos.

Cria-se, com isso, uma situação de injustiça socioambiental (MOREIRA, 2017, p. 16) a ser superada. A dimensão etno-social, neste caso, advém da necessidade de reconhecer os direitos de povos que têm identidades étnicas específicas, como os povos indígenas e tribais e outros, como as demais comunidades tradicionais que possuem condições sociais, culturais e econômicas, que os distinguem de outros setores da coletividade nacional e são regidos, total ou parcialmente, por costumes ou tradições próprios ou por legislações especiais (ver artigo $1^{\circ}$ da Convenção 169 da Organização Internacional do Trabalho - OIT). Trata-se de sujeitos de direitos que enfrentam conflitos socioambientais assim definidos por Moreira (2017, p. 21):

Entendemos por conflitos socioambientais os conflitos que envolvem disputas em torno de territórios e a natureza que lhe é intrínseca e tem como ponto comum a especial relação que os povos e comunidades tradicionais possuem com estes bens como base para a vivência social e cultural.

A introdução da Convenção 169 da OIT ${ }^{144}$ mostra como estes conflitos estão gerando a ameaça dos indígenas perderem sua identidade:

Observando que em diversas partes do mundo esses povos não podem gozar dos direitos humanos fundamentais no mesmo grau que o restante da população dos Estados onde moram e que suas leis, valores, costumes e perspectivas têm sofrido erosão frequentemente (grifo nosso).

Deborah Duprat (2015, p. 73), mostra como essa nova realidade mina a homogeneização presente no Direito Estatal e muda a natureza da relação jurídica com a terra:

Essa noção de território é um dos elementos centrais da virada paradigmática no âmbito do direito. A relação indivíduo/terra/propriedade privada, até então a única por ele homologada, passa a conviver com a de coletividades/territórios/espaços de pertencimento. A primeira, de natureza individual, com o viés da apropriação econômica; a segunda, como locus étnico e cultural (grifo nosso).

${ }^{144}$ Ver os "Considerando" da Convenção 169 da OIT citados no Decreto 5.051, de 19 de abril de 2004. 


\section{•• Série Direito, Economia e Sociedade}

O reconhecimento e a preservação dos direitos culturais das comunidades tradicionais obrigam os juristas a rever não só a interpretação de algumas leis, mas o próprio conceito de Estado, que deixa de ser monocultural para adquirir uma identidade multicultural que rompe com as regras tradicionais do direito ocidental valorizando novos sujeitos políticos. Surgem, desta maneira, novos conceitos jurídicos que colocam em crise a antiga visão monolítica de Estados nacionais, cujo conteúdo jurídico precisa ainda ser melhor definido. Duprat afirma que a Constituição Federal do Brasil de 1988 está construída sob o marco da plurietnicidade/multiculturalidade, Fajardo fala em pluriculturalidade, Santos e Menezes (2009, p. 9) escrevem que é necessário fazer a distinção entre o multiculturalismo e a interculturalidade:

Ao contrário do multiculturalismo - que pressupõe a existência de uma cultura dominante que aceita, tolera ou reconhece a existência de outras culturas no espaço cultural onde domina - a interculturalidade pressupóe o reconhecimento recíproco e a disponibilidade para enriquecimento mútuo entre várias culturas que partilham um dado espaço cultural.

O caminho para a interculturalidade é ainda longo, ainda mais que o reconhecimento da possibilidade de uma identidade nacional multicultural, que aconteceu formalmente nas normas de vários países, ainda enfrenta: "o sistema de justiça de tendência conservadora, pouco sensível aos direitos coletivos e à justiça histórica" (TRECCANI; XERFAN, 2017, p. 12).

Raquel Fajardo, comentando a Convenção 169 da OIT, ensina:

[...] o reconhecimento do caráter pluricultural do Estado/Nação/República, e o direito à identidade cultural, individual e coletiva, o que permite superar a ideia de Estado-nação monocultural e monolíngue; o reconhecimento da igual dignidade das culturas, que rompe com a supremacia institucional da cultura ocidental sobre as demais; o caráter do sujeito político dos povos e comunidades indígenas e campesinas. Os povos indígenas têm direito ao controle das suas instituições políticas, culturais e sociais e seu desenvolvimento econômico, o que permite superar o tratamento tutelar desses povos, como objeto de políticas que ditam terceiros; o reconhecimento de diversas formas de participação, consulta e representação direta de povos indígenas, campesinos e afrodescendentes. Isso supera a ideia de que apenas os funcionários públicos representam e podem formar a vontade popular; o reconhecimento do direito (consuetudinário) indígena e a jurisdição especial. Isto supōe uma forma de pluralismo jurídico interno. Todos os países andinos incorporaram na Constituição alguma fórmula de pluralismo legal reconhecendo autoridades indígenas ou campesinas, funções de justiça ou jurisdicionais, e o direito indígena ou suas próprias normas e procedimentos. Junto a isso, o reconhecimento de um conjunto de direitos relativos à terra, as formas organizacionais coletivas, educação bilíngue intercultural, oficialização de idiomas indígenas, etc. (FAJARDO, 2009, p. 30-31) (grifo nosso). 
A partir do momento em que os povos e comunidades tradicionais conseguem por fim a sua "invisibilidade" 145 política, social, econômica, cultural e reivindicar seus direitos, as concepções de Estado, de direito e de desenvolvimento assumem novas conotações. Este reconhecimento os alça à condição de "sujeitos de direito internacional" (SHIRAISHI NETO, 2007), podendo serem interlocutores, na qualidade de autores de demandas específicas, perante os organismos internacionais. Isto é, passam a ser protagonistas no cenário nacional e internacional e, quando tiverem seus direitos ameaçados ou violados, terão "capacidade de agir internacionalmente", reivindicando suas prerrogativas. Modifica-se, desta maneira, um antigo conceito de direito internacional que atribuía só aos Estados Nacionais esta "capacidade". 146

As demandas dessas populações possibilitam uma ruptura dos conceitos tradicionais de "propriedade", ruptura esta que está visível nas decisões da Corte Interamericana de Direitos Humanos, como nos mostra Eliane Moreira, depois de ter analisado dezenas de suas sentenças:

De fato, a análise dos casos apreciados pela CorteIDH e o posicionamento por ela assumido nos mostra que estamos perante uma ruptura com o conceito de propriedade moderna como verdade universal e caminhando na afirmação dos direitos territoriais coletivos numa perspectiva que, paulatinamente, nos leva a reconhecer que estes direitos não cabem no direito de propriedade e lhes impóem um claro transbordamento $[\ldots]$.

As decisões da CorteIDH representam uma requalificação profunda do direito de propriedade, marcada opor um conteúdo eminentemente latino-americano, fruto de um movimento encabeçado pelos povos e comunidades tradicionais que encontram eco no sistema interamericano de Direitos Humanos e, que, hoje, reverbera em outros sistemas, como o africano, fortemente inspirado pela jurisprudência interamericana, como no caso do Povo Ogoni vs Nigéria, por exemplo.

145 Segundo Oliveira (2017, p. 153): "As comunidades quilombolas e povos e comunidades tradicionais, por sua vez, viviam uma situação de invisibilização perante a legislação, sendo tratados nas políticas estatais sob a designação genérica e homogeneizante de "comunidades rurais".

146 A "capacidade" dos povos tradicionais peticionarem perante órgãos internacionais está expressamente prevista no artigo 12 da Convenção 169 da OIT: "Os povos interessados deverão ter proteção contra a violação de seus direitos, e poder iniciar procedimentos legais, seja pessoalmente, seja mediante os seus organismos representativos, para assegurar o respeito efetivo desses direitos [...] (Grifo nosso). Nos últimos anos estes povos já estão fazendo valer esta prerrogativa na defesa de seus direitos sócio-ambientais: segundo Moreira (2017, p. 84) a Relatoria sobre Direitos dos Povos Indígenas da Comissão Interamericana de Direitos Humanos (CIDH) elenca 31 casos em tramitação na Corte Interamericana de Direitos Humanos e 73 na CIDH. Destes 45 casos são específicos sobre meio ambiente. 


\section{•• Série Direito, Economia e Sociedade}

Apesar de terem sido historicamente discriminadas e vítimas de políticas de "genocídio" 147 e "etnocídio", em muitos países da América Latina, África e outros continentes, essas experiências continuam presentes no mundo inteiro, como afirmava em 2009 a OIT: "Os povos indígenas e tribais constituem pelo menos 5.000 povos com características distintas e uma população de mais de 370 milhões, em 70 países diferentes". Não é objetivo deste trabalho dimensionar a participação desses povos na construção de um "direito alternativo", mas tão somente destacar sua dimensão numérica e espacial. Neste sentido, é de fundamental importância perceber que com a modificação da Convenção 107, de 5 de junho de 1957, da OIT para a Convenção 169, de 27 de junho de 1989, é feita a revisão não só conceitual, substituindo a "integração" com o respeito às "diferenças". Debateu-se a quais povos/comunidades se aplicaria essa Convenção. O Informe VI Revisão parcial da Convenção sobre populações indígenas e tribais da OIT de 1987 (apud MOREIRA, 2017, p. 49) apresenta a preocupação de incluir outras comunidades não indígenas:

Se sugeriu a fórmula dos grupos tribais ou semitribais cujas condições sociais e econômicas são similares à dos grupos (indígenas), fórmula que permitiu na prática um aumento considerável dos números e dos tipos dos grupos a quem potencialmente estender os benefícios que poderiam derivar-se de um instrumento internacional. No informe, citam-se numerosos povos tribais do Próximo e Médio Oriente, entre eles, os curdos, os bakhatiares e os balúchis, que tradicionalmente cruzaram as fronteiras nacionais. Também se mencionam os grupos tribais da África, e em especial, da Etiópia, Somália, Libéria, Jamahiriya Árabe Líbia e África do Sul (tradução nossa do original em espanhol).

Um dos desafios a ser aprofundado em pesquisa específica será verificar se existe alguma semelhança entre a maneira com a qual estes povos/comunidades tradicionais latino-americanos se relacionam com a terra e os "usos cívicos" adotados por comunidades italianas.

Se durante séculos, sob a antiga égide do monismo jurídico imperou a ideologia que só o Estado poderia promulgar normas, fato que levou os Estados latinoamericanos a adotarem regimes nacionais de "integração" das minorias em seus ordenamentos jurídicos, agora tem que reconhecer a coexistência de sistemas diferentes no mesmo espaço geopolítico. Temas como gênero, raça, etnia, religião, classe, nacionalidade, etc. não só ganharam status constitucional, mas sua defesa passa a ser ponto essencial.

${ }^{147}$ Segundo o Conselho Indigenista Missionário - CIMI: "Mais de 1.470 povos indígenas foram extintos nos últimos 500 anos no Brasil”. CIMI. 2004. Povos Indígenas Extintos. 
$\mathrm{Na}$ esteira de Wolkmer (2001), podemos afirmar que as práticas adotadas pelas minorias étnicas estão produzindo um: "direito não oficial" regulamentado por normas fruto do consenso interno destes grupos. Se a tradição jurídica ocidental priorizou a hegemonia do "direito oficial", as práticas jurídicas do oriente, América Latina e África tem uma longa e antiga trajetória de utilização de "direitos não oficiais". Um dos desafios atuais será não procurar agudizar os conflitos entre estas diferentes visões, mas encontrar critérios de diálogo e interdependência.

O pluralismo jurídico coloca esses sistemas em condições de igualdade e não de subordinação normativa dando visibilidade aos povos historicamente marginalizados. São significativos os avanços registrados em algumas constituições latino-americanas que reconhecem este pluralismo, como a boliviana de 2009:

Artículo 1. Bolivia se constituye en un Estado Unitario Social de Derecho Plurinacional Comunitario, libre, independiente, soberano, democrático, intercultural, descentralizado y con autonomías. Bolivia se funda en la pluralidad y el pluralismo político, económico, jurídico, cultural y linguístico, dentro del proceso integrador del país.

A Constituição do Equador de 2008, depois de celebrar a mãe natureza, reconhece o caráter plurinacional do Estado (arts. $1^{\circ}$ e $6^{\circ}$ ):

RECONOCIENDO nuestras raíces milenarias, forjadas por mujeres y hombres de distintos pueblos, CELEBRANDO a la naturaleza, la Pacha Mama, de la que somos parte y que es vital para nuestra existencia, [...]

Art. $1^{\circ}$ El Ecuador es un Estado constitucional de derechos y justicia, social, democrático, soberano, independiente, unitario, intercultural, plurinacional y laico. [...]

Art. $6^{\circ}$ Todas las ecuatorianas y los ecuatorianos son ciudadanos y gozarán de los derechos establecidos en la Constitución. La nacionalidad ecuatoriana es el vínculo jurídico político de las personas con el Estado, sin perjuicio de su pertenencia a alguna de las nacionalidades indígenas que coexisten en el Ecuador plurinacional (grifos nossos).

A Constituição do México não é apenas uma das mais antigas da América Latina (1917), mas também uma das mais avançadas no que diz respeito ao reconhecimento da identidade específica dos povos que compõem a Nação declarando:

Art. $2^{\circ}$ La Nación Mexicana es única e indivisible.

La Nación tiene una composición pluricultural sustentada originalmente en sus pueblos indígenas que son aquellos que descienden de poblaciones que habitaban en el territorio actual del país al iniciarse la colonización y que conservan sus propias instituciones sociales, económicas, culturales y políticas, o parte de ellas. 


\section{•• Série Direito, Economia e Sociedade}

La conciencia de su identidad indígena deberá ser criterio fundamental para determinar a quiénes se aplican las disposiciones sobre pueblos indígenas. [...]

A. Esta Constitución reconoce y garantiza el derecho de los pueblos y las comunidades indígenas a la libre determinación y, en consecuencia, a la autonomía para:

I - Decidir sus formas internas de convivencia y organización social, económica, política y cultural.

II - Aplicar sus propios sistemas normativos en la regulación y solución de sus conflictos internos, sujetándose a los principios generales de esta Constitución, respetando las garantías individuales, los derechos humanos y, de manera relevante, la dignidad e integridad de las mujeres. La ley establecerá los casos y procedimientos de validación por los jueces o tribunales correspondientes.

III - Elegir de acuerdo con sus normas, procedimientos y prácticas tradicionales, a las autoridades os representantes para el ejercicio de sus formas propias de gobierno interno, garantizando la participación de las mujeres en condiciones de equidad frente a los varones, en un marco que respete el pacto federal y la soberanía de los estados [...] (grifos nossos).

Destaca-se que o princípio do auto-reconhecimento, presente no inciso II deste artigo, será o elemento essencial da Convenção 169 da Organização Internacional do Trabalho de 1989:

Artigo $1^{\circ}$

$[\ldots]$

2. A consciência de sua identidade indígena ou tribal deverá ser considerada como critério fundamental para determinar os grupos aos que se aplicam as disposições da presente Convenção.

Não se trata de o Estado reconhecer os "direitos de povos diferentes", mas de considerar estes povos e comunidades tradicionais como sujeitos políticos que estabelecem um pacto de parceria com os demais grupos sociais que integram o Estado plural.

Wolkmer (2013, p. 32) destaca o caráter inovador das recentes constituições latino-americanas:

Um constitucionalismo pluricultural comunitário, identificado com um outro paradigma não universal e único de Estado de Direito, coexistente com experiências dos "saberes tradicionais" de sociedades plurinacionais (indígenas, comunais e camponesas), com prática de pluralismo igualitário jurisdicional (convivência de instâncias legais diversas em igual hierarquia: jurisdição ordinária estatal e jurisdição indígena/ camponesa), e, finalmente, com o reconhecimento de direitos coletivos vinculado a bens comum da natureza.

O debate se concentra no conceito de território. Marés et al. (2015, p. 12-13) mostram a íntima relação entre o território e a luta pelo reconhecimento dos direitos: 
O território é o lugar da produção da cultura e dos saberes locais que tencionam a afirmação do caráter diferenciado dos direitos coletivos de povos e comunidades tradicionais. [...] Ao mesmo tempo, o território é o campo de batalha que explicita as relaçôes de poder assimétricas, as formas desiguais de acesso ao Estado, e, particularmente, à Justiça e às políticas públicas, mas também de configuração de estratégias plurais de insurgência dos grupos para tornarem-se protagonistas de suas lutas e de seus conflitos. [...] é pelas vias do protagonismo e da autodeterminação de povos e comunidades tradicionais que chegar-se-á não apenas a garantia de seus direitos, mas a própria reconstrução do Estado, pensando-o de maneira plural (grifo nosso).

O reconhecimento desses direitos se coloca totalmente contra o pensamento de Garret Hardin (1968), que apresentava como uma "tragédia dos comuns" o livre acesso aos recursos naturais por parte das populações tradicionais considerando que: "a liberdade em relação ao comum arruína todos", sugerindo sua privatização ou sua definição como propriedade pública. Adota-se a posição da economista americana Elinor Ostrom (1990), que reconhece a importância do papel dos "bens comuns".

Esta visão de "território" está diretamente ligada a uma noção de defesa do meio ambiente onde a "natureza" ganha uma noção específica como nos ensina Almeida (2007, p. 12):

A noção de "natureza" passou a ser recolocada por meio de um intenso processo de mobilização, compreendendo diversas práticas de preservação dos recursos naturais apoiadas em uma consciência ambiental aguda, e pela oposição manifesta dos movimentos sociais a interesses de empreendimentos econômicos predadores.

Esta visão peculiar de defesa do meio ambiente, em que predominam expressões como "desenvolvimento local sustentável", "conflitos socioambientais" e "participação comunitária”, pode vir a ser considerada como um dos pontos de convergência entre as experiências latino-americanas e os usi civici da Itália.

\section{USI CIVICI NA ITÁLIA (E EUROPA?)}

A discussão sobre as diferentes formas de acesso à terra na América Latina pode dialogar com outras experiências, como, por exemplo, a propriedade coletiva da gestão comunitária de alguns países europeus. Se parte da consciência que todas elas têm em comum uma afirmação de Ugo Mattei: ${ }^{148}$ "Os bens comuns não são uma mercadoria a ser considerada no âmbito do possuir. São uma prática política e cultural que pertence ao horizonte do existir juntos".

${ }^{148}$ Ver PROGETTO DOMANI CULTURA E SOLIDARIETÀ (2016). Disponível em: <http://www.prodocs.org/wp-content/uploads/201612/1.7-Un-MANIFESTO-per-i-beni-comuni_Mattei.pdf>. Acesso em: 1º dez. 2016. 
Segundo Aldo Carosi (em 16 de novembro de 2017), Vice-presidente da Corte Constitucional da República Italiana, não se podem confundir os "usos cívicos" com os domínios coletivos, pois os primeiros são mais abrangentes, incluindo os segundos (2017). Os "usos cívicos" devem ser considerados como formas de utilização do território que vêm do passado, formas heterogêneas que permitem o uso coletivo de bens imóveis públicos ou particulares relativos ao direito de caça, de pastagem, à pesca destinada a sobrevivência, ao corte de madeira. São, dessa maneira, formas de conservação de uma tradição local que determinavam o uso dos recursos naturais conforme regras estabelecidas pela própria coletividade. Não se trata, porém, de saudosismo de regimes jurídicos que pertencem ao passado, mas de realidades vivas e presentes ainda hoje baseadas na coletividade e na solidariedade.

Já Pietro Nervi (2017), Presidente do "Centro Studi e Documentazione sui Demani Civici e le Proprietà Collettive” da Universidade de Trento, os apresenta como "a perenização do potencial de produção natural existente no terreno coletivo. A visão de uma ecologia integral e de uma economia antropológica”.

Ainda na década de 1970, o debate sobre formas alternativas de propriedade encontrou em Paolo Grossi (1977) um de seus primeiros defensores. Em sua palestra de encerramento da "23 $3^{\text {a }}$ Riunione Scientifica", em 17 de novembro de 2017, Grossi lembrou a gênese do seu livro que estava sendo reeditado quarenta anos depois. Sua ideia inicial era resgatar a história do direito de propriedade. Em seus estudos preliminares, percebeu que existia uma mentalidade dominante nos diferentes doutrinadores. A cultura da civilização burguesa se baseava naquele que deveria ser um modelo único na relação entre o homem e as coisas: a propriedade individual privada, nenhum modelo concorrente poderia ser tolerado.

A análise histórica da experiência italiana dos séculos XVIII e XIX mostrava, porém, que existiam outros modelos que tinham, também, uma fundada motivação antropológica. De um lado: a antropologia do indivíduo, o indivíduo soberano que projeta sua liberdade sobre os bens, que afirma seu poder sobre os bens numa chave de absolutismo. Do outro lado existiam, porém, diferentes modelos de pensamento, baseados na terra entendida como uma realidade viva com a qual o homem deve viver em simbiose. Experiência de cunho coletivo em que se priorizava o respeito à terra e predominava a dimensão coletiva sobre a individual. A solidariedade era uma dimensão fundamental na qual os indivíduos eram amparados. Este pluralismo jurídico era sufocado pela cultura dominante. Existia, portanto, uma outra maneira de se possuir que mereceria ser aprofundada: os domínios coletivos. 
Fabrizio Marinelli (2016), da Universidade de L' Aquila, no jornal "Il Centro Cotidiano d'Abruzzo", no dia 22 de novembro de 2016 lembra a origem histórica de "usos civis" e a lei atual:

Os usos cívicos no sul da Itália, nascem como resultado das leis revolucionárias contra o feudalismo, atribuem grande parte dos domínios feudais, subtraídos aos barôes, aos cidadãos dos municípios, para que eles possam dispor de utilidades fundamentais, como apascentar as ovelhas, ou cortar madeira dos bosques na medida compatível com a manutenção dos mesmos para os invernos que viriam. A Lei 1.766 de 1927, que rege atualmente a matéria, estabelece regras como a imprescritibilidade, a inalienabilidade e a não usucapibilidade dos mesmos, a fim de evitar sua dispersão. Trata-se de propriedade coletiva muito difundidas especialmente nas montanhas, que se de um lado pode ter perdido a utilidade econômica, consiste em proteger o meio ambiente, do território e da paisagem. Uma mudança significativa, que adapta um instituto antigo ao mundo moderno e que tem sido repetidamente sublinhado de forma autoritária tanto pelo Tribunal Constitucional que pela "Corte de Cassação" (tradução nossa).

O debate sobre usi civici ganhou uma dimensão continental com a realização de um Simpósio Internacional realizado em Pieve di Cadore em 1986 (MARTIN, 1990). O simpósio apresentava formas de "propriedade coletiva agro-silvo-florestais gerenciadas comunitariamente, principalmente a nível da aldeia, ou seja, por obra de grupos sócio-territoriais ou plurifamiliares de base”. Embora vários estudos realizados naqueles anos considerassem essas realidades como "relíquias", especialmente no plano cultural, destinadas a "desaparecer para sempre", o simpósio constatou que, no entanto, essas experiências tinham uma vitalidade insuspeita, especialmente em determinadas áreas montanhosas. Apresentavam uma ligação íntima entre um grupo humano e um território específico.

As realidades estudadas apresentavam características muito semelhantes às da América Latina pois a propriedade é indivisível e o uso de determinados bens ambientais é coletivo. Por isso se trata de "uma espécie de apreensão originária do domínio e da posse de determinados bens por parte de uma comunidade plurifamiliar dos primeiros habitantes da comunidade, envolvida na manutenção de bens vitais disponíveis ao grupo" (MARTIN, 1990, p 8). Em algumas situações, a legislação italiana qualifica estas experiências de "usos cívicos"149 bens comuns que, de

149 Atualmente, segundo a sentença 01698/2013REG.PROV.COLL. da Quarta Câmara do Conselho do Estado, datada de 10 março de 2015 os: "usi civici" são direitos reais milenares de natureza coletiva, voltados a assegurar uma utilidade ou de qualquer maneira um beneficio aos que pertencem a uma coletividade”. Por isso os bens de uso cívico são normalmente inalienáveis, fora do comércio e não susceptíveis de usucapião e não integram, portanto, o "patrimônio disponível” do ente público que os gerencia. 


\section{•• Série Direito, Economia e Sociedade}

acordo com Paolo Grossi (1977), apresentam uma modalidade diferente de possuir em comparação com a concepção de propriedade individualista constante nos códigos liberais do século XIX. No Simpósio foram apresentadas várias experiências italianas e de vários outros países europeus, como Áustria, França, Grécia, Iugoslávia, Noruega, Suécia, Polónia, Rússia, Espanha, Suíça e Hungria.

Esta discussão coloca em crise os critérios de absolutismo jurídico que caracterizaram, e muitas vezes continuam a caracterizar, o pensamento legal ocidental, como mostrou Paolo Grossi (1977).

Mais recentemente, Ugo Mattei (2013, p. 2) definiu "os bens comuns como um tipo de direitos fundamentais de última geração", por isso deveriam receber uma proteção constitucional toda especial seja perante o Estado, seja do poder dos particulares. Em seu "Manifesto", Mattei entende que "pensar os bens comuns significa antes de tudo utilizar uma chave autenticamente global que póe ao centro o problema do acesso e da igualdade real das possibilidades sobre este planeta". ${ }^{150}$

Pode-se afirmar que que as formas de acesso à terra das populações tradicionais da América Latina, bem como a manutenção dos bens coletivos na Europa, têm a mesma matriz jurídica dos "bens comuns"? Este nos parece ser um desafio a ser esclarecido.

Existem, certamente, diferenças entre os territórios reivindicados pelas populações tradicionais latino-americanas e as europeias. Enquanto estas últimas procuram fazer respeitar direitos já reconhecidos há séculos, onde se unem a valorização e a preservação da paisagem presentes nos domínios das terras coletivas, os primeiros ainda estão lutando para garantir este reconhecimento. A discussão sobre os ativos cívicos, no entanto, não se esgotou a última década do século XX, mas continua até hoje. Os Encontros Científicos promovidos desde 1993 pelo "Centro Studi e Documentazione sui Demani Civici e le Proprietà" da Universidade de Trento indicam que esta temática permanece atual. Estes encontros reúnem não só especialistas de várias universidades, mas de diferentes ramos de conhecimento, pois a interdisciplinaridade é um ponto fundamental do debate.

Em 2016 o tema geral foi: "é unanimemente reconhecida pelos peritos nesta matéria a complexidade específica das estruturas de terras coletivas, como institui-

${ }^{150}$ Ver "Progetto Domani Cultura e Solidarietà" (2016), Disponível em: <http://www.prodocs. org/wp-content/uploads/201612/1.7-Un-MANIFESTO-per-i-beni-comuni_Mattei.pdf>. Acesso em: $1^{\circ} \mathrm{dez} .2016$. 
ções fundamentalmente determinadas pela propriedade coletiva de um pedaço de terra". ${ }^{151}$

O mesmo documento mostrou a importância do território como um fator de identificação da comunidade e dos seus direitos.

$\mathrm{Na}$ origem de tudo isso está o fato de uma comunidades identificada em relação ao uso coletivo de determinados bens; em outras palavras, não é a comunidade a identificar o território, mas é o território a identificar a comunidade; e usando a expressão território, se entende não só o lugar ao qual se refere o poder que a entidade exponencial do grupo - a coletividade - exerce sobre os indivíduos que fazem parte dela, mas o ponto de referência necessário e suficiente para identificar um conjunto de sujeitos ligados entre si pelo uso comum dos bens (G. LOMBARDI, 1999) (grifos nossos).

\section{PROBLEMAS A SEREM ENFRENTADOS PARA FAVORECER O DIÁLOGO ENTRE AS EXPERIÊNCIAS LATINO-AMERICANAS E EUROPEIAS}

As experiências brasileira e latino-americana mostram como o reconhecimento de direitos dos povos e populações tradicionais leva necessariamente a discutir não só qual o papel do Estado na elaboração das políticas públicas, mas, também, seu monopólio sobre o direito.

Considerando que parte considerável dos conflitos socioambientais registrados nos últimos anos atingem de maneira especial povos e comunidades tradicionais, é de fundamental importância verificar como garantir os direitos destes sujeitos sociais.

Se a luta dos povos e comunidades tradicionais brasileiros é para encontrar caminhos jurídicos para consolidar seus direitos, na Itália existem muitas experiências de propriedade/uso coletivos de bens que têm uma história secular que precisa ser resgatada, divulgada e defendida.

É necessário se perguntar se as experiências brasileiras e latino-americanas de propriedade/posse dos povos e comunidades tradicionais e as das comunidades europeias que detém "usos cívicos" possuem pontos de convergência e, caso a resposta seja positiva, se é possível uma articulação entre essas experiências. $\mathrm{O}$ uso coletivo dos

151 UNIVERSITÁ DEGLI STUDI DI TRENTO. Patrimoni collettivi e spazi identitari: le nuove risorse dello sviluppo locale. Quali strategie degli assetti fondiari collettivi. Trento, 17-18 novembre 2016. Tema Generale. Disponível em: <http://www.usicivici.unitn.it/convegni/22rs/ riunione.html>. Acesso em: 25 nov. 2016. 


\section{•• Série Direito, Economia e Sociedade}

recursos, apesar de ser objetos de normas específicas, apresenta pontos em comum? Essas formas de apropriação da terra permitem o uso sustentável dos recursos? Qual o possível papel das universidades no estímulo à troca de experiências?

Acredita-se que estes estudos conjuntos deveriam ser promovidos por universidades brasileiras, dos demais países latino-americanos e europeias. Um dos caminhos possíveis para aprofundar este debate é a análise da legislação e da jurisprudência.

Vale a pena sublinhar que este debate sobre resíduos do passado está sendo analisado na Ação Direta de Inconstitucionalidade 3.239-DF. Referindo-se aos "remanescentes das comunidades dos quilombos", o Ministro César Peluso (em voto de 18 de abril de 2012, p. 25), entendeu que: "o adjetivo remanescentes, empregado para designar coisas ou pessoas que ficam ou que subsistem, após o evento de qualquer fato (De Plácido e Silva, Vocabulário Jurídico, Forense, Vol. IV, p. 87)”. Algo, portanto, ligado ao passado, algo que existia e agora não existe mais da mesma maneira. Por seu lado a Associação Brasileira de Antropologia (1994) entende que o termo quilombo:

Não se refere a resíduos ou resquícios arqueológicos de ocupação temporal ou de comprovação biológica [...], constituem grupos étnicos conceitualmente definidos pela Antropologia como um tipo organizacional que confere pertencimento através de normas e meios empregado para indicar afiliação ou exclusão (grifo nosso).

Esta interpretação, considerada metajurídica pelo Ministro Peluso (2012), aplicada aos "remanescentes das comunidades de quilombos" brasileiros, pode ser, possivelmente, utilizada para entender as atuais experiências de "usos cívicos" na Itália e na Europa, isto é, elas não são algo que "sobra" do passado, mas experiências vivas que apontam a necessidade de uma compreensão mais ampla do universo jurídico"152.

Um último desafio a ser enfrentado no futuro será verificar a aplicação da Lei 168, de 20 novembro de 2017, que disciplina as "Normas em matéria de domínios coletivos" que entrou em vigor no dia 13 de dezembro de 2017. Seu artigo primeiro indica quais são os bens reconhecidos:

Art. $1^{\circ}$

Reconhecimento de domínios coletivos

1. Na implementação dos artigos $2^{\circ}, 9^{\circ}, 42$, segundo parágrafo e 43 da Constituição, a República reconhece os domínios coletivos, qualquer que seja sua denominação, como o sistema jurídico primário das comunidades originárias:

${ }^{152}$ Em dezembro do 2016 no Seminário: "Properties in Transformation: towards an interdisciplinary research agenda on contemporary Brazil” foi debatido o conteúdo jurídico do conceito de propriedade. Este debate merece ser aprofundado nas próximas sessões. 
a) sujeito à Constituição;

b) dotado de capacidade de auto-regulação, tanto para a administração subjetiva como a objetiva, sejas para a administração vinculante que a discricionária;

c) dotado da capacidade de gerir o patrimônio natural, econômico e cultural, que pertence à base territorial da propriedade coletiva, considerada como co-propriedade intergeracional;

d) caracterizado pela existência de uma coletividade cujos membros detêm a propriedade da terra e juntos exercem direitos de gozo mais ou menos extensos, individual ou coletivamente, em terra que o município administra ou uma comunidade da essa distinta detém como propriedade pública ou coletiva.

2 Os entes exponenciais das coletividades titulares dos direitos dos usos cívicos e da propriedade coletiva têm personalidade jurídica de direito privado e autonomia estatutária (tradução nossa do original em língua italiana).

Destaca-se que o conceito é bastante abrangente, permitindo várias formas de organização que podem assumir a responsabilidade de administrar esses bens. Quando não existirem organizações específicas, a administração será assumida pelas prefeituras. Os seus artigos segundo e terceiro dispõem sobre a valorização destes bens e suas diferentes definiçôes.

\section{CONCLUSÃO}

Este texto mostra como os caminhos para a possível interlocução entre as normas relativas a propriedades comuns ou uso coletivo dos recursos naturais na América Latina e os usi civici adotados na Europa estão em um estágio inicial e dependem de ulteriores debates. Neste momento é necessário apontar para esta possibilidade de diálogo. Só por meio de intercâmbios entre universidades chamadas a refletir sobre estas realidades e entre os próprios protagonistas destas diferentes experiências será possível consolidar esta aliança entre diferentes saberes. Este trabalho permite, desde já, uma primeira conclusão: não existe uma única forma de propriedade, as várias experiências devem ser levadas em consideração sobretudo porque tendo elas uma forte base cultural e social e uma relação especial com a terra e sua defesa como em ser vivo a respeitado é fundamental. A comparação entre as normas dos diferentes países, a análise da jurisprudência dos tribunais internacionais, as reflexóes preliminares de doutrinadores dos diferentes continentes permitem concluir que existem convergências que precisam ser aprofundadas.

Que a "Mãe Terra" inspire nossos esforços. 
•• Série Direito, Economia e Sociedade

\section{REFERÊENCIAS}

A WATCH-WORD TO THE CITY OF LONDON, and the Armie (August 26, 1649). In The (English) Digger Writings. Disponível em: <http://www.diggers.org/digger_tracts. htm>. Acesso em: $1^{\circ}$ de ago. 2017.

ACSELRAD, Henri. Apresentação. In ACSELRAD, Henri (Org.). Cartografia social, terra e território. Rio de Janeiro: IPPUR/UFRJ, 2013. p. 5-14.

ACSELRAD, Henri; VIÉGAS Rodrigo Nuñez. Cartografias sociais e território: um diálogo latino-americano. In: ACSELRAD, Henri (Org.). Cartografia social, terra e território. Rio de Janeiro: IPPUR/UFRJ. 2013. p. 15-40.

ALMEIDA, Alfredo Wagner Berno de. Apresentação. In: SHIRAISHI NETO, Joaquin (Org.). Direitos dos povos e comunidades tradicionais no Brasil: declarações, convenções internacionais e dispositivos jurídicos definidores de uma política nacional. Manaus: UEA. 2007. p. 9-17.

ALMEIDA, Alfredo Wagner Berno de; MARIN, Rosa Elizabeth Acevedo. Novas cartografia social dos povos e comunidades tradicionais do Brasil: Xukuru do Ororubá - PE. Manaus: UEA Edições, 2012.

ASSOCIAÇÃO BRASILEIRA DE ANTROPOLOGIA. Grupo de Trabalho Comunidades Negras Rurais/ABA. Documento do grupo de trabalho sobre comunidades negras rurais. Associação Brasileira de Antropologia, 1994.

BOLÍVIA. Ley 173, de 20 de septiembre de 2011. Declara de prioridad nacional la identificación de espacios para el reconocimiento a la memoria de las/los Líderes, Héroes y Próceres Indígenas Originarios Campesinos y Afrobolivianos del Estado Plurinacional de Bolivia. Disponível em: <https://www.lexivox.org/norms/BO-L-N173.pdf> Acesso em: 10 abr. 2016.

BRASIL. Constituição Politica do Imperio do Brazil de 25 de março de 1824. Disponível em: <http://www.planalto.gov.br/ccivil_03/constituicao/constituicao24.htm>. Acesso em: $1^{\circ}$ ago. 2017.

BRASIL. Decreto 5.051, de 19 de abril de 2004, Promulga a Convenção 169 da Organização Internacional do Trabalho - OIT sobre Povos Indígenas e Tribais. Diário Oficial da União de de 20 de abril de 2004.

BRASIL. Lei 3.071, de $1^{\circ}$ de janeiro de 1916. Código Civil dos Estados Unidos do Brasil. Diário Oficial da União de 5 de janeiro de 1916.

BRASIL. Lei 4.504, de 30 de novembro de 1964. Dispóe sôbre o Estatuto da Terra, e dá outras providências. Diário Oficial da União de 30 de novembro de 1964. 
BRASIL. SUPREMO TRIBUNAL FEDERAL. ADI 3.239-DF, Voto do Senhor Ministro Cezar Peluso - (Relator), 18 de abril de 2012.

CAROSI, Aldo. Palestra inicial na 23a Riunione Scientifica. UN ALTRO MODO DI POSSEDERE:DAELABORAZIONEDOTTRINALEA PROGETTO CULTURALE - Intersezione tra discipline diverse in occasione della ristampa del volume di Paolo Grossi. Trento: Università degli studi di Trento - Centro studi e documentazione sui demani civici e le proprietà collettive. 16 de novembro de 2017.

CATALANI, Pietro Maria. La funzione degli assetti fondiari collettivi nell'ordinamento, fra prospettiva storica ed attualità economico-sociale. 23a Riunione Scientifica. UN ALTRO MODO DI POSSEDERE: DA ELABORAZIONE DOTTRINALE A PROGETTO CULTURALE - Intersezione tra discipline diverse in occasione della ristampa del volume di Paolo Grossi. Trento: Università degli studi di Trento - Centro studi e documentazione sui demani civici e le proprietà collettive. 17 de novembro de 2017.

COLOMBIA. Constituicion Política de Colombia (1987). In Constituições da América Latina e do Caribe Vol. I Disponível em: <http://funag.gov.br/loja/index.php?route= product/product\&product_id=358>. Acesso em: 10 jan. 2016.

COMISSÃO PASTORAL DA TERRA. In: CANUTO, Antônio; LUZ, Cássia Regina da Silva; PINTO ANDRADE, Thiago Valentim (Coord.). Conflitos no campo. Brasil 2016. Goiânia: CPT Nacional, abril de 2017.

COMISSÃO PASTORAL DA TERRA. Conflitos no campo. Brasil 2013. Goiânia: CPT Nacional, abril de 2014.

CONSELHO INDIGENISTA MISSIONÁRIO. Povos indígenas extintos. Disponível em: <http://www.cimi.org.br/site/pt-br/index.php?system = news \&action = read \&id=598>. 27/09/2004, Acesso em: $1^{\circ}$ ago. 2017.

CONSTITUCIÓN POLÍTICA DE LOS ESTADOS UNIDOS MEXICANOS. Constitución publicada en el Diario Oficial de la Federación el 5 de febrero de 1917. Disponível em: <http://www.oas.org/juridico/mla/sp/mex/sp_mex-int-text-const.pdf>. Acesso em: 18 out. 2017.

CORTE INTERAMERICANA DE DERECHOS HUMANOS. Caso del Pueblo Saramaka vs. Surinam. Sentencia del 28 de noviembre de 2007. Disponível em: <http://www. cnj.jus.br/files/conteudo/arquivo/2016/04/ccla1e511769096f84fb5effe768fe8c.pdf>. Acesso em: 10 jan. 2015.

CORTE INTERAMERICANA DE DIREITOS HUMANOS. Caso da Comunidade Indigena Yakye Axa Vs. Paraguai Sentença de 17 de junho de 2005. Disponível em: <http:// www.cnj.jus.br/files/conteudo/arquivo/2016/04/357a11f7d371f11cba840b78dde6d3e7. pdf.> Acesso em: 10 jan. 2015.

COSTITUZIONE DI WEIMAR (11.8.1919), Disponível em: <http://www.dircost. unito.it/cs/pdf/19190811_germaniaWeimar_ita.pdf>. Acesso em: 18 out. 2017. 


\section{•- Série Direito, Economia e Sociedade}

DUGUIT, Leon, Les Transformations générales du Droit privé depuis le Code Napoléon. Paris: Librairie Félix Alcan. 1912. Disponível em: <http://gallica.bnf.fr/ark:/12148/ bpt6k935172d/f1.image>. Acesso em: 18 out. 2017.

DUPRAT, Debora. O direito sobre o marco da plurietnicidade/multiculturalidade. In: DUPRAT, Debora (Org). Pareceres jurídicos: direito dos povos e comunidades tradicionais. Manaus: UEA, 2007. p. 9-19.

DUPRAT, Deborah. A Convenção 169 da OIT e o direito à consulta prévia, livre e informada. In: DUPRAT. (Org.). Convenção 169 da OIT e os Estados Nacionais. Brasília: ESMPU, 2015. p. 53-78. Disponível em: <https://escola.mpu.mp.br/linha-editorial/ outras publicacoes/CONVENCaO\%20169\%20DA\%20OIT_Web.pdf >. Acesso em: 6 nov. 2016.

FAJARDO, Raquel Z. Yrigoyen. Aos 20 anos da Convenção 169 da OIT: balanço e desafios da implementação dos direitos dos Povos Indígenas na América Latina. In: VERDUM, Ricardo. (Org.). Povos indígenas: Constituições e Reformas Políticas na América Latina. Brasília: Instituto de Estudos socioeconômicos, 2009. p. 9-62. Disponível em: <http://perso.unifr.ch/derechopenal/assets/files/obrasportales/op_20090918_01. pdf>. Acesso em: 8 nov. 2016.

FELLET, João. Governo Temer trava demarcações de áreas quilombolas. Disponível em: <http://www.bbc.com/portuguese/brasil-39625624>. Acesso em: 20 abr. 2017.

FRANÇA. Code Civil des français. Disponível em: <https://fr.wikisource.org/wiki/ Code_civil_des_Fran\%C3\%A7ais_1804/Texte_entier>. Acesso em: 10 ago. 2017.

GROSSI, Paolo. Assolutismo giuridico e diritto privato. Milano: Giuffrè Editore. 1998.

GROSSI, Paolo. Un altro modo di possedere. L'emersione di forme alternative di proprietà alla coscienza giuridica postunitaria. Milano 1977.

GROSSI, Paulo, Palestra Final da 23a Riunione Scientifica. UN ALTRO MODO DI POSSEDERE: DAELABORAZIONEDOTTRINALEAPROGETTOCULTURALE - Intersezione tra discipline diverse in occasione della ristampa del volume di Paolo Grossi. Trento: Università degli studi di Trento - Centro studi e documentazione sui demani civici e le proprietà collettive. 17 de novembro de 2017.

HARDIN, Garret. The tragedy of commons. Science, v. 162, p. 1243-1248, 1968.

HONDURAS, Ley de Propiedad (Decreto 82-2004): La presente Ley tiene como propósito fortalecer y otorgar seguridad jurídica a los titulares de la propiedad, desarrollar y ejecutar una política nacional que permita la inversión nacional y extranjera y el acceso a la propiedad por parte de todos los sectores de la sociedad. Publicado no Diario Oficial de la Republica de Honduras, 29 de junho de 2004.

MARINELLI, Fabrizio. L'abolizione degli usi civici una iattura per gli abruzzesi. "Il Centro", quotidiano dell'Abruzzo, martedì 22 novembre 2016. p. 37. Disponibile In: <http:// 
www.usicivici.unitn.it/download/newsletter/20161213_1804ArticoloUsiciviciIlCentro. pdf $>$. Accesso em: 23 di gennaio 2017.

MARTIN, Gian Candido (Org.). Comunità di Villaggio e proprietà collettive in Italia e in Europa. Contributi al Simposio internazionale di Pieve di Cadore, 15-16 settembre 1986. Padova: Giunta Regionale del Veneto - CEDAM. 1990.

MATTEI, Ugo. Beni comuni. Un manifesto. Roma: Laterza. Ebook. 2013.

MOREIRA, Eliane Cristina Pinto. Justiça sócioambiental e direitos humanos: uma análise a partir dos direitos territoriais dos povos e comunidades tradicionais. Rio de Janeiro: Lumen Juris. 2017.

MOREIRA, Eliane; PIMENTEL, Melissa. O direito à autoidentificação de povos e comunidades tradicionais no Brasil. Revista Fragmentos de Cultura, Goiânia, v. 5, 2, p. 159-170, abr/jun. 2015.

NEGÓCIO, Ramon de Vasconcelos; CIPRIANO, Rodrigo Carneiro (Org.). Constituiçōes da América Latina e Caribe. Brasília: FUNAG, 2010.

NERVI, Pietro. Palestra inicial na 23a Riunione Scientifica. Un altro modo di possedere: da elaborazione dottrinale a progetto culturale - Intersezione tra discipline diverse in occasione della ristampa del volume di Paolo Grossi. Trento: Università degli studi di Trento - Centro studi e documentazione sui demani civici e le proprietà collettive. 16 de novembro de 2017.

NICARAGUA. Constituicion Política de Nicaragua (1987). In: Constituições da América Latina e do Caribe, v. III Disponível em: <http://funag.gov.br/loja/index.php?route= product/product\&product_id=358>. Acesso em: 10 jan. 2016.

ORGANIZACIÓN INTERNACIONAL DEL TRABAJO (OIT). Los Derechos de Los Pueblos Indígenas Y Tribales En La Práctica Una Guia Sobre El Convenio 169 De La OIT. Disponível em: <http://www.aecid.es/Centro-Documentacion/Documentos/ Publicaciones\%20AECID/6.\%20Implementaci\%C3\%B3n\%20Convenio\%20169\%20 -\%20ILO.pdf>. Acesso em: $1^{\circ}$ ago. 2017.

OSTROM, Elinor. Governing The Commons The evolution of institutions for collective action. Cambridge Universite Press, 1990.

PANAMA. Ley 9, de 30 de mayo de 2000: declara el 30 de mayo de cada año Día Cívico y de Conmemoración de la Etnia Negra Nacional, que se celebrará en todo el territorio de la República con el propósito de resaltar sus valores y aportes a la cultura y al desarrollo del país. Disponível In, Gaceta Oficial: 24064 Publicada el: 31-05-2000. <https://docs. panama.justia.com/federales/leyes/9-de-2000-may-31-2000.pdf>. Acesso em: $10 \mathrm{fev}$. 2017.

PERU, Ley 28.495, de 06 de abril de 2005: Ley del Instituto Nacional de Desarrollo de Pueblos Andinos, Amazónicos y Afroperuano. Disponível em: <https://www.migraciones. gob.pe/documentos/normalegal_11.pdf>. Acesso em: 10 fev. 2017. 


\section{•• Série Direito, Economia e Sociedade}

PROGETTO DOMANI CULTURA E SOLIDARIETÀ. MATTEI, Ugo UN MANIFESTO PER I BENI COMUNI Disponível em: <http://www.prodocs.org/wp-content/ uploads/201612/1.7-Un-MANIFESTO-per-i-beni-comuni_Mattei.pdf $>$. Acesso em: 10 dez. 2016.

QUAGLIONI, Diego, Palestra na 23a Riunione Scientifica. UN ALTRO MODO DI POSSEDERE: DAELABORAZIONEDOTTRINALEA PROGETTOCULTURALE - Intersezione tra discipline diverse in occasione della ristampa del volume di Paolo Grossi. Trento: Università degli studi di Trento - Centro studi e documentazione sui demani civici e le proprietà collettive. 17 de novembro de 2017.

RAPOZO, Pedro, Territórios Sociais da Pesca. Usos e formas de apropriação comum dos recursos pesqueiros em áreas de livre acesso. Manaus: Editora da Universidade Federal do Amazonas. 2015.

REPPUBLICA ITALIANA. Codice Civile. Edizione giugno 2017. Disponível em: <http://www.altalex.com/ /media/Altalex/allegati/2017/ebook-gratuiti/codice-civilegiugno_2017\%20pdf\%20pdf.pdf>. Acesso em: 10 ago. 2017.

REPPUBLICA ITALIANA. Legge 168, de 20 novembro de 2017, "Norme im materia di domini colettivi” G. U. 28/11/2017. Disponível em: <http://www.altalex.com/documents/ leggi/2017/11/02/domini-collettivi-legge-tutela-territori>. Acesso em: 8 dez. 2017.

REPPUBLICA ITALIANA. Legge 431, 8 agosto 1985. Conversione in Legge, con modificazioni, del Decreto-Legge 27 Giugno 1985, 312, Recante Disposizioni Urgenti per la tutela delle Zone di Particolare Interesse Ambientale (GU 197 de 22 di agosto de 1985).

ROCHA, Ibraim; TRECCANI, Girolamo Domenico; BENATTI, José Heder; HABER, Lilian Mendes; CHAVES, Rogério Arthur Friza. Manual de direito agrário constitucional. Liçôes de direito agroambiental. 2. ed. Belo Horizonte: Fórum, 2015.

SANTOS, Boaventura de Sousa; MENESES, Maria Paula, Introdução. In: SANTOS, Boaventura de Sousa; MENESES, Maria Paula (Org.). Epistemologias do Sul. Coimbra: Ediçôes Almedina AS, 2009.

SHIRAISHI NETO, Joaquim. Leis do Babaçu livre. Praticas jurídicas das quebradeiras de coco e normas correlatas. Manaus: PPGSCA-UFAM/F FORD, 2006.

SHIRAISHI NETO, Joaquin. A participação do Universal: povos e comunidades tradicionais face às declarações e Convençôes Internacionais. In: SHIRAISHI NETO, Joaquin (Org.). Direitos dos povos e comunidades tradicionais no Brasil: declaraçôes, convenções internacionais e dispositivos jurídicos definidores de uma política nacional. Manaus: UEA, 2007.

SILVA, Kalina Vanderlei Silva; MACIEL, Henrique Silva. Dicionário de Conceitos Históricos. São Paulo: Contexto, 2009.

SOUZA FILHO, Carlos Frederico Marés de; et al. Direitos territoriais de povos e comunidades tradicionais em situação de conflitos socioambientais. Brasília: IPDMS, 2015. 
TRECCANI, Girolamo Domenico. Demarcação de terras indígenas ACO 312. In: Jurisprudência Constitucional Revisada. Uma homenagem da advocacia paraense aos 25 anos da Constituição Federal. Rio de Janeiro: GZ Editora, 2014, v. 1, p. 13-38.

TRECCANI, Girolamo Domenico. Terras de quilombo: caminhos e entraves do processo de titulação. Belém: autor, 2006 p.344.

TRECCANI, Girolamo Domenico; XERFAN, Renato da Cruz. Etnocídio versus Etnodesenvolvimento: o drama dos povos indígenas do Xingu. 2017. No prelo.

UNIVERSITÀ DEGLI STUDI DI TRENTO. Dipartimento di Economia e Management -Facoltà di Giurisprudenza. Centro Studi e Documentazione sui Demani civici e le Proprietà collettive. $22^{\wedge}$ Riunione Scientifica: Patrimoni collettivi e spazi identitari: le nuove risorse dello sviluppo locale. Quali strategie degli assetti fondiari collettivi Trento. 17-18 novembre 2016. Disponibile In: <http://www.usicivici.unitn.it/convegni/22rs/ riunione.html>. Accesso: 25 nov. 2016.

VAN WETTER, P. Pandectes. Paris: LGDJ, 1909. t. 2.

VIANA, Aurélio. Destinação de terras públicas devolutas e terras comunitárias na Amazônia. Mimeo, 2010.

WOLKMER, Antonio Carlos. Pluralismo crítico e perspectivas para um novo constitucionalismo na América Latina. In: WOLKMER, Antonio Carlos; MELO, Milena Patters. Constitucionalismo latino-americano tendências contemporâneas. Curitiba: Juruá, 2013.

WOLKMER, Antonio Carlos. Pluralismo jurídico. Fundamentos de uma cultura no direito. São Paulo: Alfa Omega. 2001. 
